\title{
Review \\ Gut Microbiota and Intestinal Trans-Epithelial Permeability
}

\author{
Bénédicte Allam-Ndoul ${ }^{1,2}$, Sophie Castonguay-Paradis ${ }^{1,2,3}$ and Alain Veilleux ${ }^{1,2,3, *(1)}$
}

1 Centre Nutrition, Santé et Société (NUTRISS), Institut sur la Nutrition et les Aliments Fonctionnels (INAF), Université Laval, Québec, QC G1V 0A6, Canada; benedicte.allam-ndoul@criucpq.ulaval.ca (B.A.-N.); sophie.castonguay-paradis.1@ulaval.ca (S.C.-P.)

2 Canada Research Excellence Chair in the Microbiome-Endocannabinoidome Mediators Axis in Metabolic Health (CERC-MEND), Université Laval, Québec, QC G1V 0A6, Canada

3 École de Nutrition, Faculté des Sciences de L'Agriculture et de L'Alimentation (FSAA), Université Laval, Québec, QC G1V 0A6, Canada

* Correspondence: alain.veilleux@fsaa.ulaval.ca; Tel.: +1-418-656-2131

Received: 11 August 2020; Accepted: 31 August 2020; Published: 3 September 2020

\begin{abstract}
Constant remodeling of tight junctions to regulate trans-epithelial permeability is essential in maintaining intestinal barrier functions and thus preventing diffusion of small molecules and bacteria to host systemic circulation. Gut microbiota dysbiosis and dysfunctional gut barrier have been correlated to a large number of diseases such as obesity, type 2 diabetes and inflammatory bowel disease. This led to the hypothesis that gut bacteria-epithelial cell interactions are key regulators of epithelial permeability through the modulation of tight junctions. Nevertheless, the molecular basis of host-pathogen interactions remains unclear mostly due to the inability of most in vitro models to recreate the differentiated tissue structure and components observed in the normal intestinal epithelium. Recent advances have led to the development of a novel cellular model derived from intestinal epithelial stem cells, the so-called organoids, encompassing all epithelial cell types and reproducing physiological properties of the intestinal tissue. We summarize herein knowledge on molecular aspects of intestinal barrier functions and the involvement of gut bacteria-epithelial cell interactions. This review also focuses on epithelial organoids as a promising model for epithelial barrier functions to study molecular aspects of gut microbiota-host interaction.
\end{abstract}

Keywords: intestinal epithelial organoids; small intestine; colon; gut microbiota; trans-epithelial permeability; tight junction

\section{Introduction}

Mucosal surfaces, including the pulmonary tree, the genitourinary tract or the gastrointestinal tract, are covered by a layer of epithelial cells forming the interface of the body with the external environment [1]. The gastrointestinal mucosa is a semipermeable barrier allowing the absorption of nutrients, whole body homeostasis regulation and immune sensing, while limiting the passage of potentially harmful antigens and microorganisms from the intestinal lumen. This complex system includes, from the luminal to the basolateral surface, the gut microbiota, the mucus layer, the epithelial cell monolayer and immune cells in the lamina propria. The mucus layer and the epithelial cell monolayer act as a physical barrier, which forbade bacterial adhesion and regulate trans-epithelial diffusion of small molecules and bacteria to host systemic circulation. As for the lamina propria and the submucosa, they organize the immune response to face the passage of commensal and pathogenic microbes [2,3]. The regulation of trans-epithelial permeability is achieved by the tight junctions (TJ), which mechanically link epithelial cells together. Gut bacteria-epithelial cell interactions have been 
suggested as key contributors of TJ remodeling and so of epithelial permeability. Of note, dysregulation of the gut microbiota is tightly associated to the pathogenesis of several chronic diseases harboring intestinal permeability alterations, such as obesity, type 2 diabetes (T2D) and inflammatory bowel disease (IBD) [4-6]. This review proposes to briefly cover intestinal barrier components and functions in obesity and to explore bacteria-host interaction in the regulation of intestinal barrier function.

\section{Components of the Intestinal Barrier}

\subsection{Gut Microbiota}

The term gut microbiota refers to the microorganism community residing in the gut lumen. Adult gut microbiota harbors approximately $10^{13}$ bacterial cells [7] from more than 250 different species of bacteria as well as fungi, viruses and archaea. Human gut bacteria are mainly from the Firmicutes (60 to $80 \%$ ), the Bacteroidetes (20 to $40 \%$ ), the Proteobacteria and the Actinobacteria phylum [8-11] however, their relative abundances fluctuate according to the anatomical location and are highly variable among individuals [12]. Although gut microbiota composition can rapidly be altered by drugs, diet and other environmental factors, it is relatively resilient in the long term [13]. Host and gut microbiota communities co-exist in a highly mutualistic relationship that has crucial impacts on health status [14]. In fact, the host needs the gut microbiota to support diverse gut and systemic physiological functions, namely nutrient metabolism, maintenance of an optimal metabolic homeostasis and prevention of intestinal colonization by pathogenic bacteria.

\subsection{Intestinal Mucosa}

The intestinal mucosa is the innermost layer of the intestinal tract. It includes the epithelium, an underlying lamina propria of highly vascularized interstitial tissue, and the muscularis mucosae, which provide support and mobility to the mucosa [1,2]. The intestinal mucosa is overlaid with a discontinuous mucus layer that forms a highly organized glycoprotein network. Mucus is mainly composed of mucin proteins, especially Mucin 2, secreted by specialized epithelial cells called Goblet cells. This gel-like structure acts as a physical barrier, permeable to water and small molecules, limiting direct contact between the contents of the gut lumen and epithelial cells [15]. It also displays antimicrobial properties through the action of secreted antimicrobial peptides (i.e., defensins and $\operatorname{IgA}$ ) but also represents an important bacterial niche. The thickness and the composition of the mucus layer influences the properties of this bacterial niche, whilst the bacteria can also impact the properties of the mucus layer [16].

The intestinal epithelium is composed of a polarized cell monolayer of absorptive enterocytes, Paneth cells, Goblet cells and enteroendocrine cells. It is the most crucial component of the physical intestinal barrier separating the lamina propria from the lumen [3]. Junctions between epithelial cells, established by the adherens junctions, must be strong but malleable to cope with the movements and stretches of the intestinal tract. These junctions are also crucial to maintain epithelium polarity, which allows the directional transport of nutrients and the secretion of enzymes and antimicrobial peptides into the lumen.

\subsection{Tight Junctions}

Tight junctions consist of a network of transmembrane protein strands that interacting and link laterally adjacent cells near the apical surface of the epithelium [17]. These transmembrane proteins include large families of claudin proteins, TJ-associated MARVEL domain-containing proteins (TAMPs) and junctional adhesion molecules (JAMs) as well as a variety of cytoplasmic adaptor and scaffolding proteins [18].

Both cis- and trans-homophilic interactions of claudin proteins within the transcellular space create a barrier or pores enabling selective ion permeability and thus are major determinants of trans-epithelial transport [19]. At least 27 members of the claudin family have been identified, some 
with barrier functions for small molecules and others, such as claudin-2, with pore-forming properties for ions and water [20]. Of note, the knockout of claudin 7 [21] or claudin 2 and 15 [22] members in mice caused intestinal barrier disturbances. The TAMP protein family, i.e., occludins, tricellulin and MarvelD3, are mainly involved in cis-homophilic interactions along the cell membrane. Their presence appears as essential for TJ formation and maintenance; however, their precise roles remain unclear [23] Single-span transmembrane protein members of the JAM family form a multitude of intracellular and extracellular molecular interactions, which regulate TJ assembly and functions [24]. Combination and spatial layout of these proteins allow tissue-specific TJ permeability as well as dynamic regulation of the TJ properties to adapt to changing environmental conditions such as diet and microbiota.

TJ proteins are linked to the actin-based cytoskeleton through adaptor and scaffolding molecules. These interactions are crucial to maintain gut epithelial integrity by detecting mechanical stress and by coordinating changes in protein expression and assembly accordingly [25]. Scaffolding proteins belonging to the zonula occludens family (ZO-1, ZO-2 and ZO-3) are the best-known multidomain proteins. ZO-1 is essential in coordinating $\mathrm{TJ}$ formation and cell polarization as it establishes links between most transmembrane TJ proteins (i.e., claudins, TAMPs and JAMs) and cytoskeleton components [26].

These complex multiprotein structures create an essential barrier against potentially harmful pathogens and molecules in the lumen. TJ are highly dynamic and can adapt to the changing environment. However, environmental, and cellular events may partially or completely disrupt the intestinal barrier leading to chronically increased intestinal permeability and allowing intrusion of harmful environmental components into systemic circulation. A dysfunctional barrier is a common feature of obesity and T2D [27].

\subsection{Intestinal Barrier Function in Obesity and T2D}

Obesity is an important global health problem, which is associated with increased risk of cardiometabolic complications, such as T2D [28]. These conditions share low-grade inflammation as well as alterations in the intestinal barrier function. The compromised epithelial barrier arises from changes in TJ protein expression or modifications of key intracellular and extracellular molecular interactions facilitating the passage of potentially harmful bacterial antigens and microorganisms from the intestinal lumen to systemic circulation [29].

Pro-inflammatory lipopolysaccharide (LPS) from some Gram-negative bacteria has been identified as a key contributing factor in the initiation and the progression of low-grade inflammation in presence of leaky gut [27]. Under normal conditions, the intestinal epithelium prevents LPS translocation, but in diet-induced obesity (DIO) as well as in obesity and T2D mice model ( $d b / d b)$ higher circulating LPS levels and low-grade inflammation in peripheral tissues are noted [30]. Moreover compared to lean control mice, DIO and $d b / d b$ mice showed a higher trans-epithelial permeability and a modified distribution of ZO-1 in the intestinal mucosa [31]. Such alteration in gut permeability is accompanied by a decreased expression of several TJ proteins, i.e., ZO-1, occludin [32,33]. In humans, upper gastrointestinal tract trans-epithelial permeability, measured by urinary sucrose recovery, is elevated in presence of obesity [34]. However, obesity may not be the most critical determinant of intestinal barrier dysfunction as hyperglycemia strongly interfered with intestinal barrier integrity (i.e., decrease ZO-1 mucosal staining and increased fluorescent-dextran absorption) in obese and T2D mice [35]. Hyperglycemia was established as a direct cause of intestinal barrier dysfunction as treatment of this condition, but not obesity, rescued glucose-induced barrier alterations in mice [35]. Similarly, inadequate glycemic control in humans has been associated with increased translocation of microbial products in the circulation [35]. Intestinal permeability is also increased along with the severity of liver steatosis in obese subjects [31,36]. These demonstrations underline that obesity-related complications are closely associated with altered intestinal barrier functions. Although the precise mechanisms linking metabolic complications to intestinal permeability remain unclear, the literature suggests an active role of the gut microbiota. 


\subsection{Gut Microbiota Dysbiosis}

Gut bacterial communities have a high degree of plasticity and their composition can be affected by numerous environmental and host factors such as diet, age, physiological state and genetic background. Gut dysbiosis, characterized by an imbalance in the composition and activity of gut microbial communities, has been associated with the development of several diseases [5,37]. Fecal microbiota transfer and germ-free animal studies have established a causal link between gut microbiota dysbiosis and diseases such as obesity and enteropathies [38,39]. Changes in the metabolic activity of gut microbiota, such as its capacity to harvest energy from nutrients, may contribute to the establishment of these diseases [40] but the role of more complex gut microbiota-host interactions are being explored.

It is often acknowledged that the relative abundance of the two main gut microbiota phyla, i.e., Bacteroidetes and Firmicutes, is altered in obesity such that the Firmicutes-to-Bacteroidetes ratio is higher in obese subjects [41,42]. In fact, some studies found that Bacteroidetes are positively associated with leanness and weight loss, whereas Firmicutes and Proteobacteria are generally positively associated with low quality diet, obesity and metabolic complications [43,44]. Even though some of these findings have been recently challenged, the contribution of gut microbiota in obesity-related complications is undeniable and far more complex than a simple imbalance in phylum relative abundance $[45,46]$.

The impact of specific genera and species within these microbial phyla are not necessarily consistent. Indeed, the Lactobacillus genus, belonging to the Firmicutes phylum, has been associated with obesity and T2D [47] while some species of this genus, i.e., Lactobacillus paracasei and Lactobacillus plantarum appear to have a protective effect against weight gain [48,49]. Obesity and T2D have been associated with a lower relative abundance of Bacteroides and Bifidobacterium genera as well as butyrate-producing bacteria Faecalibacterium prausnitzii [50,51] and Roseburia intestinalis genera [52]. Interestingly, bariatric surgery increased F. prausnitzii relative abundance concomitantly with an amelioration of glucose homeostasis, low-grade inflammation and gut epithelial permeability in subjects with T2D [53,54]. This species is one of the main butyrate-producing bacteria, a key energy source for intestinal epithelial cells [55]. Butyrate has been shown to reduce local inflammation and to improve gut barrier permeability through several mechanisms among which mucin synthesis [56], TJ reassembly [57] or occludin and ZO-1 up-regulation [58]. Bacteroides vulgatus and Bacteroides dorei, two species potentially beneficial for T2D, have been shown to increase the expression of ZO-1 and to improve epithelial barrier function [59]. These bacteria can produce bacteriocins, proteins that inhibit growth of specific bacteria, which could participate in the development or reversal of dysbiosis by limiting the growth of harmful strains [60]. Akkermansia muciniphila, a mucin-degrading strain belonging to the Verrucomicrobia phylum, colonizes the intestinal mucus layer where it ameliorated intestinal barrier integrity directly by promoting mucin production [61] and indirectly through interactions with other bacteria $[62,63]$. This species has consistently been associated with leanness, insulin sensitivity and lessened low-grade inflammation [62,64]. Interestingly, either pasteurized or live A. muciniphila were able to reduce gut barrier permeability and to improve glucose metabolism in obese mice [64,65]. Finally, the relative abundance of the main LPS-producing Gram-negative bacteria is modified in obesity. Indeed, imbalanced or dysbiotic gut microbiota tends to shift away from less potent Bacteroidetes LPS in favor of more pro-inflammatory Proteobacteria LPS [66,67]. Increased pro-inflammatory endotoxin levels in dysbiotic gut microbiota may in turn exacerbate the low-grade inflammatory state by increasing trans-epithelial permeability, which facilitates translocation of even more pro-inflammatory LPS into the circulation $[63,68]$.

A tripartite interrelation between metabolic complications, intestinal barrier function and gut bacteria seems to emerge from recent literature. Environmental and host diseases-related factors impact both gut microbiota composition and intestinal barrier integrity. As described, bacteria and gut microbiota-derived factors are also direct modulators of the intestinal barrier integrity. Yet, the precise molecular bases of gut microbiota-host interaction remain unclear. Obtaining comprehensive knowledge from relevant models of intestinal barrier function will be crucial to establish mechanisms 
of interactions to develop strategies to resolve epithelial barrier dysfunctions and alleviate ensuing metabolic complications.

\subsection{Bacteria-Host Interaction and Intestinal Barrier Function}

\subsubsection{Intestinal Epithelial Organoids}

Immortalized epithelial cell lines (e.g., Caco-2, HT-29 and T84) have permitted breakthrough in gut mucosal physiology for decades but have several weaknesses and limitations $[69,70]$. Recent advances have led to the development of a novel cellular model derived from intestinal epithelial stem cells, the so-called epithelial organoids. These organoids are three-dimensional self-renewing cellular structures embedded in extracellular matrix maintaining their organ-specific cell lineage [71]. Intestinal epithelial organoids reproduce villus-like structures and crypt-like proliferative zones, which encompass all epithelial cell types [72]. Intestinal epithelial organoids can be derived from freshly isolated intestinal crypts holding multipotent adult stem cells (ASCs) or from pluripotent stem cells (PSCs) [71]. PSCs emanate either from embryonic stem cells (ESCs) or from patient somatic cells which undergo reprogramming into a pluripotent state (iPSCs) [73]. These cultures a remarkably stable, both phenotypically and genetically. Intestinal organoids have thus rapidly provided novel knowledge on the pathophysiology of several enteropathies [74,75]. Interestingly, these polarized epithelial cells establish functional TJ complexes [71,76] and secrete mucus onto the apical surface of the epithelium $[77,78]$, which confirms the added value of using epithelial organoids as a model to study epithelial barrier functions in the gut.

Most anaerobic bacteria in the gut microbiota are not viable in the aerobic environment needed to harvest intestinal cell lines, limiting interaction studies to bacterial lysates and conditioned media rather than living bacteria. This limitation can be overcome using intestinal epithelial organoids as their intraluminal space is sealed within the mucus layer, the epithelium and the extracellular matrix, which allows for the establishment of slight hypoxia in the lumen (i.e., 5 to $15 \%$ of oxygen) [79]. Furthermore, epithelial organoids include, by definition, only epithelial cells. The absence of immune and stromal cells provides the opportunity to investigate direct bacteria-epithelial cell interactions.

Microinjection methods are needed to inoculate living aerotolerant or anaerobic bacteria in the organoid lumen for a short period of time [79]. Studies using monoculture and complex bacterial communities resulted in stable colonization to investigate gut bacteria-epithelial cell interaction $[78,80,81]$. While this approach is valuable and is the most widely used, it remains challenging due to equipment and skills required for microinjection in organoid lumen $(<250 \mu \mathrm{m})$. Alternative monolayer culture methods allowing easy access to the apical surface of the epithelium were developed for large-scale experiments. Monolayer and three-dimensional cultures are thus complementary and together represent promising avenues to study cellular and molecular aspects of gut bacteria-epithelial cell interactions.

The next section reviews studies in which gut microbiota-host interactions were investigated using intestinal epithelial organoids to identify the cellular and molecular mechanisms involved in the regulation of epithelial barrier functions by gut bacteria. Table 1 details such studies. The use of bacterial and viral infections in intestinal epithelial organoids described below can be used as a model that could, at least in part, reflect gut microbiota-host interactions present in states of obesity-related gut dysbiosis.

\subsubsection{Clostridium difficile}

Clostridium difficile is an anaerobic, Gram-positive, toxin-producing bacillus which is a major infectious cause of nosocomial diarrhea [82]. The virulence of this emerging pathogen is mostly conferred by two large proteins: C. difficile toxins A (TcdA) and C. difficile toxin B (TcdB) [83]. Both toxins have potent glucosyltransferase activity leading to cytotoxicity. 
Table 1. Studies reporting gut microbiota-epithelial cell interactions using intestinal epithelial organoids.

\begin{tabular}{|c|c|c|c|c|c|}
\hline Bacteria and Viruses & Strain and Type & Host and Segment & Culture Method & Study Outcome(s) & Ref \\
\hline \multirow{2}{*}{ Clostridium difficile } & 1870 & Human iPSC & Matrix-embedded & $\downarrow$ mucin production (mucin 2) & [78] \\
\hline & VPII 10463 & Human iPSC & Matrix-embedded & $\begin{array}{l}\uparrow \text { trans-epithelial permeability (TcdA toxin > TcdB toxin) Alteration of } \\
\text { ZO-1 and occludin expression }\end{array}$ & [79] \\
\hline Cryptosporidium paroum & - & Mouse Adult stem cells & Matrix-embedded & $\downarrow$ epithelial cell growth & [84] \\
\hline \multirow[t]{4}{*}{ Escherichia coli } & Non-pathogenic ECOR2 & Human ESC & Matrix-embedded & $\begin{array}{l}\text { Colonization of the organoid lumen with } E \text {. coli } \\
\text { Regulates adherents junctions and other cell-cell interactions } \\
\uparrow \text { epithelial mucus secretion. } \\
\downarrow \text { IFN- } \gamma \text {-induced trans-epithelial permeability }\end{array}$ & [81] \\
\hline & Shiga toxin-producing O157:H7 & Human iPSC & Matrix-embedded & $\downarrow$ epithelial barrier integrity & [85] \\
\hline & Shiga toxin-producing O157:H7 & Mouse iPSC & Matrix-embedded & $\begin{array}{l}\uparrow \mathrm{TJ} \text { proteins (TJ protein 2, occludin and claudin-1) and mucin proteins } \\
\uparrow \text { trans-epithelial permeability }\end{array}$ & [86] \\
\hline & Enterohemorrhagic EDL933 & Human ASC Colon & Monolayer & $\begin{array}{l}\downarrow \text { mucus production (mucin } 2 \text { ) } \\
\downarrow \text { protocadherin } 24 \text { protein and TJ proteins (Occludin). }\end{array}$ & [87] \\
\hline \multirow[t]{2}{*}{ Lactobacillus } & L. rhamnossus GG & Human ASC small intestine & Matrix-embedded & $\begin{array}{l}\uparrow \text { occludin and ZO- } 1 \text { expression } \\
\downarrow \text { IFN- } \gamma \text {-induced trans-epithelial permeability () }\end{array}$ & {$[88]$} \\
\hline & L. reuteri D8 & Mouse ASC small intestine & Matrix-embedded & $\begin{array}{l}\uparrow \text { intestinal epithelial cell proliferation } \\
\text { Decreases trans-epithelial permeability }\end{array}$ & [89] \\
\hline \multirow[t]{2}{*}{ Salmonella entetica } & Serovar Typhimurium 14028 & Mouse ASC small intestine & Matrix-embedded & $\begin{array}{l}\downarrow \mathrm{TJ} \text { complexes and TJ proteins (ZO- } 1 \text { and occludin) } \\
\uparrow \text { claudin-2 protein }\end{array}$ & [90] \\
\hline & Serovar typhimurium SL1344 & Human iPSC & Matrix-embedded & Invades organoids epithelial barrier & [91] \\
\hline Shigella flexneri & $2457 \mathrm{~T}$ & Human ASC small intestine & Monolayer & $\uparrow$ mucus production (Muc2) & [92] \\
\hline \multirow[t]{3}{*}{ Enteroviruses } & CVB3, EV-71, E11 & Human ESC & Matrix-embedded & $\begin{array}{l}\uparrow \text { cytotoxicity (Enterovirus E11) } \\
\uparrow \text { misclocalization of occludin } \\
\downarrow \text { crypt morphology and integrity }\end{array}$ & [93] \\
\hline & A71 & Human ESC & Monolayer & $\uparrow$ trans-epithelial permeability & [94] \\
\hline & A71 & Human ESC & Monolayer & $\begin{array}{l}\downarrow \text { Mucin- } 1 \text { and } 2 \text { production } \\
\text { No impact on epithelial barrier function }\end{array}$ & [95] \\
\hline
\end{tabular}

iPSC: Induced pluripotent stem cells; ECS: Embryonic stem cells; ASC: Adult stem cells. 
Viable C. difficile were microinjected into the lumen of intestinal epithelial organoids and able to persist for at least $12 \mathrm{~h}$ [79]. This illustrates the capacity of intestinal epithelial organoids to create a slightly anaerobic niche allowing the culture of anaerobes, at least for a short period of time. Colonization of the epithelial organoids with a toxigenic $C$. difficile strain triggered a complete disruption of the epithelium. Loss of epithelial barrier function was accompanied by an important redistribution of the TJ proteins ZO-1 and occludin as well as an important down-regulation of mucin 2 expression [78]. All these effects were reproduced by microinjection of TcdA, but not of TcdB, in organoids.

C. difficile infection is also associated with increased mucosal levels of pro-inflammatory cytokines (i.e., IFN- $\gamma$ and TNF- $\alpha$ ), which are capable of disrupting TJ and epithelial integrity in organoids as for $C$. difficile toxins [96]. Host STAT5-dependent JAK2 signaling pathway is necessary to initiate the production of anti-inflammatory cytokines and to promote intestinal epithelium repair. By taking advantage of genetically modified organoids, Liu et al. demonstrated the involvement of a defective JAK2-STAT5 signaling in the susceptibility to $C$. difficile infection. Indeed, constitutive activation of this pathway is sufficient to restore the expression of $\mathrm{TJ}$ proteins and to maintain epithelium integrity in organoids exposed to pro-inflammatory cytokines or C. difficile toxins [96].

In summary, these results demonstrate that viable bacteria can persist in the lumen of intestinal epithelial organoids and that such coculture models can be valuable in the mechanistic study of interactions between gut bacteria and intestinal epithelial barrier functions. Importantly, three-dimensional intestinal organoids display a physiologically relevant response to $C$. difficile colonization, which facilitates knowledge translation of the observed molecular and cellular events to in vivo situations.

\subsubsection{Escherichia coli}

Shiga toxin (Stx)-producing Escherichia coli, including the O157:H7 strain, are involved in the development of acute bloody diarrheal diseases and are commonly associated with foodborne outbreaks [97]. Developing effective interventions for diseases caused by Stx-producing E. coli is of importance as such infections can lead to the development of life-threatening systemic complications such as hemolytic uremic syndrome and kidney failure [98]. Until now, research lacked effective experimental models to properly investigate human-restricted pathogens such as Shiga toxin-producing E. coli.

Pradhan and al. investigated the impact of two major forms of Shiga toxins, i.e., Stx1 and Stx2a, on gut barrier function using intestinal epithelial organoids [86]. Significant dose- and time-dependent increases in trans-epithelial permeability were observed in organoids exposed to both types of Stx toxins, either in the luminal and the basolateral compartments. Microinjection of the more potent toxin, Stx2a, in human intestinal organoids triggered a paradoxical up-regulation of several key structural and TJ proteins, i.e., ZO-2, occludin and claudin- 1 , as well as mucin 2 expression. To assess susceptibility to Stx in vivo, human intestinal epithelial organoids were transplanted under the kidney capsule of mice for two months, where they developed large mucous-filled lumens with native crypt-villus architecture. Injection of Stx2a in the lumen of in vivo organoids caused blood accumulation in the villi and mesenchyme of the transplants, epithelial damages and apoptosis [85].

In another study, human colonic epithelial organoids were cultured as monolayers to investigate Shiga toxin-producing E. coli-epithelial cell interactions [87]. Four hours post-infection, mucin layer thickness and mucin 2 labelling were significantly reduced, which allowed E. coli to directly interact with the epithelium. Within $18 \mathrm{~h}$, the infection induced an important redistribution of occludin from the TJ complexes to the cytosol and a concomitant decrease of the trans-epithelial electrical resistance, a marker of altered epithelial permeability. Thus, human intestinal epithelial organoids, either as a monolayer, matrix-embedded or transplanted in mice, represent an interesting model to investigate cellular and molecular aspects of pathogen-host interactions especially in the context of intestinal barrier function. 


\subsubsection{Lactobacillus rhamnosus GG}

Probiotics are currently defined as "live microorganisms that, when administered in adequate amounts confer a health benefit on the host" [99]. The beneficial role of probiotics relies on their ability to impede gut pathogen colonization, to modulate host immune response and to enhance the intestinal epithelial functions, among others [99,100].

Lactobacillus rhamnosus GG (LGG) is a probiotic originally isolated from the intestinal tract of a healthy subject, which has been extensively used for its various health benefits. It has clinically been shown to improve IBD symptoms and to maintain remission of ulcerative colitis [101]. Using organoids, Han et al. investigated the protective role of LGG on epithelial barrier functions by incubating human intestinal epithelial organoids with fecal supernatants of IBD patients or healthy subjects in the presence or absence of LGG [88]. Intriguingly, fecal supernatants from IBD patients, but not from healthy subjects, increased trans-epithelial permeability only in the absence of LGG supplementation. LGG conditioned media restored epithelial barrier functions after a barrier disruption by pro-inflammatory cytokines by normalizing TJ protein expressions, especially ZO-1 and occludin. Interestingly, only secreted metabolites, and not bacterial cell wall or bacterial DNA, were able to prevent IFN- $\gamma$-induced epithelial damages.

Identification of soluble factors mediating the effects of probiotics, or more generally of gut bacteria, represent an opportunity to understand their mechanism of action as well as to develop effective pharmacological strategies to circumvent issues posed using live bacteria. This study showed the relevance of using intestinal epithelial organoid as a simplified, but highly relevant, in vitro model to unravel the mechanisms involved in bacterial-epithelial cell interactions.

\subsubsection{Viral Infections}

Viral infection is the most frequent cause of gastroenteritis in humans, being involved in more than $60 \%$ of diarrhea symptoms [102]. Norovirus and rotavirus are highly prevalent in the gastrointestinal tract, which spread through contaminated foods, surfaces or fecal-oral transmission. Viral replication takes place within the gut lumen and requires direct interaction with the intestinal epithelium [103]. There is, to our knowledge, no study investigating the impact of viral infection on intestinal barrier functions in organoid models. Nevertheless, it has been shown that intestinal epithelial organoids are an excellent in vitro model to study rotavirus infections.

Absence of pharmaceutical prevention or treatment strategies for some virus, such as human noroviruses (HuNoVs) is partly due to the lack of relevant in vivo and in vitro infection models. Ettayebi et al. exploited human intestinal epithelial organoids as a monolayer culture to demonstrate that $\mathrm{HuNoVs}$ can replicate in vitro [104]. Interestingly, these cultures also recapitulate genotype-specific patterns of HuNoV susceptibility as cell cultures with the secretor positive genotype (Fucosyltransferase 2, FUT2) were more susceptible to viral infections than cultures isolated from secretor negative individuals. This observation mirrors epidemiologic data suggesting that HuNoV infection is dependent on the expression of genetically determined histoblood groups. Similarly, Yin and al. demonstrated the ability of murine and human organoids to support rotavirus infections [105]. Indeed, SA11 rotavirus replicons were detected in mice and human epithelial organoids $24 \mathrm{~h}$ post-incubation. Viral infection was associated with increased INF- $\gamma$-mediated innate immune response of host cells.

These studies suggest that it is conceivable to take advantage of intestinal epithelial organoids to investigate the impact of viruses on intestinal barrier functions. Patient-derived organoids can be used to study the pathogenesis of gastroenteritis and to support development of new therapeutics. Use of such organoids also revealed that the genetic and pathophysiological background of the stem cell donors must be taken into consideration but can also represent a promising avenue to address interindividual variability in gut microbiota-host interactions. 


\section{Conclusions}

Alterations in gut epithelial permeability and gut microbiota dysfunction are both tightly associated to the pathogenesis of several chronic diseases, such as obesity and type 2 diabetes (T2D). Gut bacteria-epithelial cell interactions have been suggested as a key contributor of epithelial permeability in several segments of the gastrointestinal tract. In fact, several studies support the notion that bacteria can regulate TJ expression and assembly, and thus regulate trans-epithelial permeability. This review has discussed opportunities of using intestinal organoid as in vitro study models of gut microbiota-epithelial cell interactions. While most studies have focused on human pathogens, the use of bacterial and viral infections in intestinal epithelial organoids represents an excellent opportunity to study the interactions of individual species or more complex bacterial communities with gut physiology in states of gut dysbiosis. Comprehensive knowledge about the role of the gut microbiota on intestinal barrier function from a highly relevant model, i.e., epithelial organoids, will be crucial in developing strategies to resolve epithelial barrier dysfunctions in several non-infectious chronic diseases.

Author Contributions: B.A.-N. conceived and wrote the manuscript; S.C.-P. wrote the manuscript; A.V. supervised the scientific work and edited the manuscript. All authors have read and agreed to the published version of the manuscript.

Funding: Work leading to this review was financially supported by the Canadian Institutes of Health Research (A.V., DOL342964), the Fonds de recherche du Québec-Santé (A.V., 33219) and the Canada Research Excellence Chair in the Microbiome-Endocannabinoidome Axis in Metabolic Health (CERC04), which is funded by the Tri-Agency of the Canadian Federal Government (Canadian Institutes of Health Research (CIHR), Natural Sciences and Engineering Research Council of Canada (NSERC), and Social Sciences and Humanities Research Council of Canada (SSHRC). This work was also supported by the Canadian Foundation of Innovation (AV). S.C.-P. received scholarships from NUTRISS Center and Diabète Québec.

Conflicts of Interest: The authors declare no conflict of interest.

\section{References}

1. Buckley, A.; Turner, J.R. Cell Biology of Tight Junction Barrier Regulation and Mucosal Disease. Cold Spring Harb. Perspect. Biol. 2018, 10, a029314. [CrossRef] [PubMed]

2. Vancamelbeke, M.; Vermeire, S. The intestinal barrier: A fundamental role in health and disease. Expert Rev. Gastroenterol. Hepatol. 2017, 11, 821-834. [CrossRef] [PubMed]

3. Odenwald, M.A.; Turner, J.R. The intestinal epithelial barrier: A therapeutic target? Nat. Rev. Gastroenterol. Hepatol. 2017, 14, 9-21. [CrossRef] [PubMed]

4. Chu, H.; Khosravi, A.; Kusumawardhani, I.P.; Kwon, A.H.K.; Vasconcelos, A.C.; Cunha, L.D.; Mayer, A.E.; Shen, Y.; Wu, W.-L.; Kambal, A.; et al. Gene-microbiota interactions contribute to the pathogenesis of inflammatory bowel disease. Science 2016, 352, 1116-1120. [CrossRef]

5. Patterson, E.; Ryan, P.M.; Cryan, J.F.; Dinan, T.G.; Ross, R.P.; Fitzgerald, G.F.; Stanton, C. Gut microbiota, obesity and diabetes. Postgrad. Med. J. 2016, 92, 286-300. [CrossRef]

6. Nishida, A.; Inoue, R.; Inatomi, O.; Bamba, S.; Naito, Y.; Andoh, A. Gut microbiota in the pathogenesis of inflammatory bowel disease. Clin. J. Gastroenterol. 2018, 11, 1-10. [CrossRef]

7. Sender, R.; Fuchs, S.; Milo, R. Revised Estimates for the Number of Human and Bacteria Cells in the Body. PLoS Biol. 2016, 14, e1002533. [CrossRef]

8. Ley, R.E.; Peterson, D.A.; Gordon, J.I. Ecological and Evolutionary Forces Shaping Microbial Diversity in the Human Intestine. Cell 2006, 124, 837-848. [CrossRef]

9. Rinninella, E.; Raoul, P.; Cintoni, M.; Franceschi, F.; Miggiano, G.; Gasbarrini, A.; Mele, M. What is the Healthy Gut Microbiota Composition? A Changing Ecosystem across Age, Environment, Diet, and Diseases. Microorganisms 2019, 7, 14. [CrossRef]

10. Vieira-Silva, S.; Falony, G.; Darzi, Y.; Lima-Mendez, G.; Garcia Yunta, R.; Okuda, S.; Vandeputte, D.; Valles-Colomer, M.; Hildebrand, F.; Chaffron, S.; et al. Species-function relationships shape ecological properties of the human gut microbiome. Nat. Microbiol. 2016, 1, 16088. [CrossRef]

11. MetaHIT Consortium (Additional Members); Arumugam, M.; Raes, J.; Pelletier, E.; Le Paslier, D.; Yamada, T.; Mende, D.R.; Fernandes, G.R.; Tap, J.; Bruls, T.; et al. Enterotypes of the human gut microbiome. Nature 2011, 473, 174-180. [CrossRef] 
12. Faith, J.J.; Guruge, J.L.; Charbonneau, M.; Subramanian, S.; Seedorf, H.; Goodman, A.L.; Clemente, J.C.; Knight, R.; Heath, A.C.; Leibel, R.L.; et al. The Long-Term Stability of the Human Gut Microbiota. Science 2013, 341, 1237439. [CrossRef] [PubMed]

13. Wilson, A.S.; Koller, K.R.; Ramaboli, M.C.; Nesengani, L.T.; Ocvirk, S.; Chen, C.; Flanagan, C.A.; Sapp, F.R.; Merritt, Z.T.; Bhatti, F.; et al. Diet and the Human Gut Microbiome: An International Review. Dig. Dis. Sci. 2020, 65, 723-740. [CrossRef] [PubMed]

14. Lozupone, C.A.; Stombaugh, J.I.; Gordon, J.I.; Jansson, J.K.; Knight, R. Diversity, stability and resilience of the human gut microbiota. Nature 2012, 489, 220-230. [CrossRef] [PubMed]

15. Schroeder, B.O. Fight them or feed them: How the intestinal mucus layer manages the gut microbiota. Gastroenterol. Rep. 2019, 7, 3-12. [CrossRef]

16. Bergstrom, K.S.B.; Kissoon-Singh, V.; Gibson, D.L.; Ma, C.; Montero, M.; Sham, H.P.; Ryz, N.; Huang, T.; Velcich, A.; Finlay, B.B.; et al. Muc2 Protects against Lethal Infectious Colitis by Disassociating Pathogenic and Commensal Bacteria from the Colonic Mucosa. PLoS Pathog. 2010, 6, e1000902. [CrossRef]

17. Zihni, C.; Mills, C.; Matter, K.; Balda, M.S. Tight junctions: From simple barriers to multifunctional molecular gates. Nat. Rev. Mol. Cell Biol. 2016, 17, 564-580. [CrossRef]

18. Capaldo, C.T.; Powell, D.N.; Kalman, D. Layered defense: How mucus and tight junctions seal the intestinal barrier. J. Mol. Med. 2017, 95, 927-934. [CrossRef]

19. Tsukita, S.; Tanaka, H.; Tamura, A. The Claudins: From Tight Junctions to Biological Systems. Trends Biochem. Sci. 2019, 44, 141-152. [CrossRef]

20. Lu, Z.; Ding, L.; Lu, Q.; Chen, Y.-H. Claudins in intestines: Distribution and functional significance in health and diseases. Tissue Barriers 2013, 1, e24978. [CrossRef]

21. Tanaka, H.; Takechi, M.; Kiyonari, H.; Shioi, G.; Tamura, A.; Tsukita, S. Intestinal deletion of Claudin-7 enhances paracellular organic solute flux and initiates colonic inflammation in mice. Gut 2015, 64, 1529-1538. [CrossRef]

22. Wada, M.; Tamura, A.; Takahashi, N.; Tsukita, S. Loss of Claudins 2 and 15 From Mice Causes Defects in Paracellular Na+ Flow and Nutrient Transport in Gut and Leads to Death from Malnutrition. Gastroenterology 2013, 144, 369-380. [CrossRef] [PubMed]

23. Garcia-Hernandez, V.; Quiros, M.; Nusrat, A. Intestinal epithelial claudins: Expression and regulation in homeostasis and inflammation: Intestinal epithelial claudins. Ann. N. Y. Acad. Sci. 2017, 1397, 66-79. [CrossRef] [PubMed]

24. Reglero-Real, N.; Colom, B.; Bodkin, J.V.; Nourshargh, S. Endothelial Cell Junctional Adhesion Molecules: Role and Regulation of Expression in Inflammation. Arterioscler. Thromb. Vasc. Biol. 2016, 36, 2048-2057. [CrossRef] [PubMed]

25. Balda, M.S.; Matter, K. Tight junctions as regulators of tissue remodelling. Curr. Opin. Cell Biol. 2016, 42, 94-101. [CrossRef]

26. Ikenouchi, J.; Umeda, K.; Tsukita, S.; Furuse, M.; Tsukita, S. Requirement of ZO-1 for the formation of belt-like adherens junctions during epithelial cell polarization. J. Cell Biol. 2007, 176, 779-786. [CrossRef]

27. Cani, P.D.; Amar, J.; Iglesias, M.A.; Poggi, M.; Knauf, C.; Bastelica, D.; Neyrinck, A.M.; Fava, F.; Tuohy, K.M.; Chabo, C.; et al. Metabolic Endotoxemia Initiates Obesity and Insulin Resistance. Diabetes 2007, 56, 1761-1772. [CrossRef]

28. Engin, A. The Definition and prevalence of obesity and metabolic syndrome. In Obesity and Lipotoxicity; Engin, A.B., Engin, A., Eds.; Advances in Experimental Medicine and Biology; Springer International Publishing: Cham, Switzerland, 2017; Volume 960, pp. 1-17. ISBN 978-3-319-48380-1.

29. Winer, D.A.; Luck, H.; Tsai, S.; Winer, S. The Intestinal Immune System in Obesity and Insulin Resistance. Cell Metab. 2016, 23, 413-426. [CrossRef]

30. Clemente-Postigo, M.; Oliva-Olivera, W.; Coin-Aragüez, L.; Ramos-Molina, B.; Giraldez-Perez, R.M.; Lhamyani, S.; Alcaide-Torres, J.; Perez-Martinez, P.; El Bekay, R.; Cardona, F.; et al. Metabolic endotoxemia promotes adipose dysfunction and inflammation in human obesity. Am. J. Physiol. Endocrinol. Metab. 2019, 316, E319-E332. [CrossRef]

31. Miele, L.; Valenza, V.; La Torre, G.; Montalto, M.; Cammarota, G.; Ricci, R.; Mascianà, R.; Forgione, A.; Gabrieli, M.L.; Perotti, G.; et al. Increased intestinal permeability and tight junction alterations in nonalcoholic fatty liver disease. Hepatology 2009, 49, 1877-1887. [CrossRef] 
32. Cani, P.D.; Bibiloni, R.; Knauf, C.; Waget, A.; Neyrinck, A.M.; Delzenne, N.M.; Burcelin, R. Changes in Gut Microbiota Control Metabolic Endotoxemia-Induced Inflammation in High-Fat Diet-Induced Obesity and Diabetes in Mice. Diabetes 2008, 57, 1470-1481. [CrossRef] [PubMed]

33. Poritz, L.S.; Garver, K.I.; Green, C.; Fitzpatrick, L.; Ruggiero, F.; Koltun, W.A. Loss of the Tight Junction Protein ZO-1 in Dextran Sulfate Sodium Induced Colitis. J. Surg. Res. 2007, 140, 12-19. [CrossRef] [PubMed]

34. Wilbrink, J.; Bernards, N.; Mujagic, Z.; van Avesaat, M.; Pijls, K.; Klaassen, T.; van Eijk, H.; Nienhuijs, S.; Stronkhorst, A.; Wilms, E.; et al. Intestinal barrier function in morbid obesity: Results of a prospective study on the effect of sleeve gastrectomy. Int. J. Obes. 2020, 44, 368-376. [CrossRef] [PubMed]

35. Thaiss, C.A.; Levy, M.; Grosheva, I.; Zheng, D.; Soffer, E.; Blacher, E.; Braverman, S.; Tengeler, A.C.; Barak, O.; Elazar, M.; et al. Hyperglycemia drives intestinal barrier dysfunction and risk for enteric infection. Science 2018, 359, 1376-1383. [CrossRef]

36. Damms-Machado, A.; Louis, S.; Schnitzer, A.; Volynets, V.; Rings, A.; Basrai, M.; Bischoff, S.C. Gut permeability is related to body weight, fatty liver disease, and insulin resistance in obese individuals undergoing weight reduction. Am. J. Clin. Nutr. 2017, 105, 127-135. [CrossRef]

37. Cresci, G.A.; Bawden, E. Gut Microbiome: What We Do and Don't Know. Nutr. Clin. Pract. 2015, 30, 734-746. [CrossRef]

38. Ni, J.; Wu, G.D.; Albenberg, L.; Tomov, V.T. Gut microbiota and IBD: Causation or correlation? Nat. Rev. Gastroenterol. Hepatol. 2017, 14, 573-584. [CrossRef]

39. Abenavoli, L.; Scarpellini, E.; Colica, C.; Boccuto, L.; Salehi, B.; Sharifi-Rad, J.; Aiello, V.; Romano, B.; De Lorenzo, A.; Izzo, A.A.; et al. Gut Microbiota and Obesity: A Role for Probiotics. Nutrients 2019, 11, 2690. [CrossRef]

40. Kim, B.; Choi, H.-N.; Yim, J.-E. Effect of Diet on the Gut Microbiota Associated with Obesity. J. Obes. Metab. Syndr. 2019, 28, 216-224. [CrossRef]

41. Gérard, P. Gut microbiota and obesity. Cell. Mol. Life Sci. 2016, 73, 147-162. [CrossRef]

42. Mitev, K.; Taleski, V. Association between the Gut Microbiota and Obesity. Open Access Maced. J. Med. Sci. 2019, 7, 2050-2056. [CrossRef] [PubMed]

43. Gomes, A.C.; Hoffmann, C.; Mota, J.F. The human gut microbiota: Metabolism and perspective in obesity. Gut Microbes 2018, 1-18. [CrossRef] [PubMed]

44. Gao, X.; Zhang, M.; Xue, J.; Huang, J.; Zhuang, R.; Zhou, X.; Zhang, H.; Fu, Q.; Hao, Y. Body Mass Index Differences in the Gut Microbiota Are Gender Specific. Front. Microbiol 2018, 9, 1250. [CrossRef] [PubMed]

45. John, G.K.; Mullin, G.E. The Gut Microbiome and Obesity. Curr. Oncol. Rep. 2016, 18, 45. [CrossRef]

46. Magne, F.; Gotteland, M.; Gauthier, L.; Zazueta, A.; Pesoa, S.; Navarrete, P.; Balamurugan, R. The Firmicutes/Bacteroidetes Ratio: A Relevant Marker of Gut Dysbiosis in Obese Patients? Nutrients 2020, 12, 1474. [CrossRef]

47. Ibrahim, M.; Anishetty, S. A meta-metabolome network of carbohydrate metabolism: Interactions between gut microbiota and host. Biochem. Biophys. Res. Commun. 2012, 428, 278-284. [CrossRef]

48. Zuo, H.-J. Gut bacteria alteration in obese people and its relationship with gene polymorphism. World J. Gastroenterol. 2011, 17, 1076. [CrossRef]

49. F.S.Teixeira, T.; Grześkowiak, Ł.M.; Salminen, S.; Laitinen, K.; Bressan, J.; do Carmo Gouveia Peluzio, M. Faecal levels of Bifidobacterium and Clostridium coccoides but not plasma lipopolysaccharide are inversely related to insulin and HOMA index in women. Clin. Nutr. 2013, 32, 1017-1022. [CrossRef]

50. Andoh, A.; Nishida, A.; Takahashi, K.; Inatomi, O.; Imaeda, H.; Bamba, S.; Kito, K.; Sugimoto, M.; Kobayashi, T. Comparison of the gut microbial community between obese and lean peoples using $16 \mathrm{~S}$ gene sequencing in a Japanese population. J. Clin. Biochem. Nutr. 2016, 59, 65-70. [CrossRef]

51. Hippe, B.; Remely, M.; Aumueller, E.; Pointner, A.; Magnet, U.; Haslberger, A.G. Faecalibacterium prausnitzii phylotypes in type two diabetic, obese, and lean control subjects. Benef. Microbes 2016, 7, 511-517. [CrossRef]

52. Qin, J.; Li, Y.; Cai, Z.; Li, S.; Zhu, J.; Zhang, F.; Liang, S.; Zhang, W.; Guan, Y.; Shen, D.; et al. A metagenome-wide association study of gut microbiota in type 2 diabetes. Nature 2012, 490, 55-60. [CrossRef] [PubMed]

53. Carlsson, A.H.; Yakymenko, O.; Olivier, I.; Håkansson, F.; Postma, E.; Keita, Å.V.; Söderholm, J.D. Faecalibacterium prausnitzii supernatant improves intestinal barrier function in mice DSS colitis. Scand. J. Gastroenterol. 2013, 48, 1136-1144. [CrossRef] [PubMed] 
54. Furet, J.-P.; Kong, L.-C.; Tap, J.; Poitou, C.; Basdevant, A.; Bouillot, J.-L.; Mariat, D.; Corthier, G.; Doré, J.; Henegar, C.; et al. Differential adaptation of human gut microbiota to bariatric surgery-induced weight loss: Links with metabolic and low-grade inflammation markers. Diabetes 2010, 59, 3049-3057. [CrossRef] [PubMed]

55. Duncan, S.H.; Hold, G.L.; Harmsen, H.J.M.; Stewart, C.S.; Flint, H.J. Growth requirements and fermentation products of Fusobacterium prausnitzii, and a proposal to reclassify it as Faecalibacterium prausnitzii gen. nov., comb. nov. Int. J. Syst. Evol. Microbiol. 2002, 52, 2141-2146. [CrossRef] [PubMed]

56. Willemsen, L.E.M. Short chain fatty acids stimulate epithelial mucin 2 expression through differential effects on prostaglandin E1 and E2 production by intestinal myofibroblasts. Gut 2003, 52, 1442-1447. [CrossRef]

57. Miao, W.; Wu, X.; Wang, K.; Wang, W.; Wang, Y.; Li, Z.; Liu, J.; Li, L.; Peng, L. Sodium Butyrate Promotes Reassembly of Tight Junctions in Caco-2 Monolayers Involving Inhibition of MLCK/MLC2 Pathway and Phosphorylation of PKC $\beta 2$. Int. J. Mol. Sci. 2016, 17, 1696. [CrossRef]

58. Ma, X.; X. Fan, P.; Li, L.S.; Qiao, S.Y.; Zhang, G.L.; Li, D.F. Butyrate promotes the recovering of intestinal wound healing through its positive effect on the tight junctions1. J. Anim. Sci. 2012, 90, 266-268. [CrossRef]

59. Yoshida, N.; Emoto, T.; Yamashita, T.; Watanabe, H.; Hayashi, T.; Tabata, T.; Hoshi, N.; Hatano, N.; Ozawa, G.; Sasaki, N.; et al. Bacteroides vulgatus and Bacteroides dorei Reduce Gut Microbial Lipopolysaccharide Production and Inhibit Atherosclerosis. Circulation 2018, 138, 2486-2498. [CrossRef]

60. Drissi, F.; Merhej, V.; Angelakis, E.; El Kaoutari, A.; Carrière, F.; Henrissat, B.; Raoult, D. Comparative genomics analysis of Lactobacillus species associated with weight gain or weight protection. Nutr. Diabetes 2014, 4, e109. [CrossRef]

61. Ottman, N.; Reunanen, J.; Meijerink, M.; Pietilä, T.E.; Kainulainen, V.; Klievink, J.; Huuskonen, L.; Aalvink, S.; Skurnik, M.; Boeren, S.; et al. Pili-like proteins of Akkermansia muciniphila modulate host immune responses and gut barrier function. PLOS ONE 2017, 12, e0173004. [CrossRef]

62. Macchione, I.G.; Lopetuso, L.R.; Ianiro, G.; Napoli, M.; Gibiino, G.; Rizzatti, G.; Petito, V.; Gasbarrini, A.; Scaldaferri, F. Akkermansia muciniphila: Key player in metabolic and gastrointestinal disorders. Eur. Rev. Med. Pharmacol. Sci. 2019, 23, 8075-8083. [CrossRef] [PubMed]

63. Chelakkot, C.; Choi, Y.; Kim, D.-K.; Park, H.T.; Ghim, J.; Kwon, Y.; Jeon, J.; Kim, M.-S.; Jee, Y.-K.; Gho, Y.S.; et al. Akkermansia muciniphila-derived extracellular vesicles influence gut permeability through the regulation of tight junctions. Exp. Mol. Med. 2018, 50, e450. [CrossRef] [PubMed]

64. Plovier, H.; Everard, A.; Druart, C.; Depommier, C.; Van Hul, M.; Geurts, L.; Chilloux, J.; Ottman, N.; Duparc, T.; Lichtenstein, L.; et al. A purified membrane protein from Akkermansia muciniphila or the pasteurized bacterium improves metabolism in obese and diabetic mice. Nat. Med. 2017, 23, 107-113. [CrossRef]

65. Shin, N.-R.; Lee, J.-C.; Lee, H.-Y.; Kim, M.-S.; Whon, T.W.; Lee, M.-S.; Bae, J.-W. An increase in the Akkermansia spp. population induced by metformin treatment improves glucose homeostasis in diet-induced obese mice. Gut 2014, 63, 727-735. [CrossRef] [PubMed]

66. Salguero, M.V.; Al-Obaide, M.A.I.; Singh, R.; Siepmann, T.; Vasylyeva, T.L. Dysbiosis of Gram-negative gut microbiota and the associated serum lipopolysaccharide exacerbates inflammation in type 2 diabetic patients with chronic kidney disease. Exp. Ther. Med. 2019, 18, 3461-3469. [CrossRef] [PubMed]

67. d'Hennezel, E.; Abubucker, S.; Murphy, L.O.; Cullen, T.W. Total Lipopolysaccharide from the Human Gut Microbiome Silences Toll-Like Receptor Signaling. mSystems 2017, 2. [CrossRef]

68. Boulangé, C.L.; Neves, A.L.; Chilloux, J.; Nicholson, J.K.; Dumas, M.-E. Impact of the gut microbiota on inflammation, obesity, and metabolic disease. Genome Med. 2016, 8, 42. [CrossRef]

69. Balimane, P.V.; Chong, S. Cell culture-based models for intestinal permeability: A critique. Drug Discov. Today 2005, 10, 335-343. [CrossRef]

70. Ahmed, D.; Eide, P.W.; Eilertsen, I.A.; Danielsen, S.A.; Eknæs, M.; Hektoen, M.; Lind, G.E.; Lothe, R.A. Epigenetic and genetic features of 24 colon cancer cell lines. Oncogenesis 2013, 2, e71. [CrossRef]

71. Clevers, H. Modeling Development and Disease with Organoids. Cell 2016, 165, 1586-1597. [CrossRef]

72. Kretzschmar, K.; Clevers, H. Organoids: Modeling Development and the Stem Cell Niche in a Dish. Dev. Cell 2016, 38, 590-600. [CrossRef] [PubMed]

73. Wiegand, C.; Banerjee, I. Recent advances in the applications of iPSC technology. Curr. Opin. Biotechnol. 2019, 60, 250-258. [CrossRef] [PubMed]

74. Fatehullah, A.; Tan, S.H.; Barker, N. Organoids as an in vitro model of human development and disease. Nat. Cell Biol. 2016, 18, 246-254. [CrossRef] 
75. Meneses, A.; Schneeberger, K.; Kruitwagen, H.; Penning, L.; van Steenbeek, F.; Burgener, I.; Spee, B. Intestinal Organoids-Current and Future Applications. Vet. Sci. 2016, 3, 31. [CrossRef] [PubMed]

76. Xu, P.; Becker, H.; Elizalde, M.; Masclee, A.; Jonkers, D. Intestinal organoid culture model is a valuable system to study epithelial barrier function in IBD. Gut 2018, 67, 1905-1906. [CrossRef] [PubMed]

77. Johansson, M.E.V.; Phillipson, M.; Petersson, J.; Velcich, A.; Holm, L.; Hansson, G.C. The inner of the two Muc2 mucin-dependent mucus layers in colon is devoid of bacteria. Proc. Natl. Acad. Sci. USA 2008, 105, 15064-15069. [CrossRef] [PubMed]

78. Engevik, M.A.; Yacyshyn, M.B.; Engevik, K.A.; Wang, J.; Darien, B.; Hassett, D.J.; Yacyshyn, B.R.; Worrell, R.T. Human Clostridium difficile infection: Altered mucus production and composition. Am. J. Physiol. Gastrointest. Liver Physiol. 2015, 308, G510-G524. [CrossRef]

79. Leslie, J.L.; Huang, S.; Opp, J.S.; Nagy, M.S.; Kobayashi, M.; Young, V.B.; Spence, J.R. Persistence and Toxin Production by Clostridium difficile within Human Intestinal Organoids Result in Disruption of Epithelial Paracellular Barrier Function. Infect. Immun. 2015, 83, 138-145. [CrossRef]

80. Williamson, I.A.; Arnold, J.W.; Samsa, L.A.; Gaynor, L.; DiSalvo, M.; Cocchiaro, J.L.; Carroll, I.; Azcarate-Peril, M.A.; Rawls, J.F.; Allbritton, N.L.; et al. A High-Throughput Organoid Microinjection Platform to Study Gastrointestinal Microbiota and Luminal Physiology. Cell. Mol. Gastroenterol. Hepatol. 2018, 6, 301-319. [CrossRef]

81. Hill, D.R.; Huang, S.; Nagy, M.S.; Yadagiri, V.K.; Fields, C.; Mukherjee, D.; Bons, B.; Dedhia, P.H.; Chin, A.M.; Tsai, Y.-H.; et al. Bacterial colonization stimulates a complex physiological response in the immature human intestinal epithelium. eLife 2017, 6, e29132. [CrossRef]

82. Hall, A.J.; Curns, A.T.; McDonald, L.C.; Parashar, U.D.; Lopman, B.A. The Roles of Clostridium difficile and Norovirus Among Gastroenteritis-Associated Deaths in the United States, 1999-2007. Clin. Infect. Dis. 2012, 55, 216-223. [CrossRef] [PubMed]

83. Papatheodorou, P.; Barth, H.; Minton, N.; Aktories, K. Cellular Uptake and Mode-of-Action of Clostridium difficile Toxins. In Updates on Clostridium difficile in Europe; Mastrantonio, P., Rupnik, M., Eds.; Advances in Experimental Medicine and Biology; Springer: Cham, Switzerland, 2018; Volume 1050, pp. 77-96. ISBN 978-3-319-72798-1.

84. Zhang, X.-T.; Gong, A.-Y.; Wang, Y.; Chen, X.; Lim, S.-Y.S.; Dolata, C.E.; Chen, X.-M. Cryptosporidium parvum infection attenuates the ex vivo propagation of murine intestinal enteroids. Physiol. Rep. 2016, 4, e13060. [CrossRef] [PubMed]

85. Karve, S.S.; Pradhan, S.; Ward, D.V.; Weiss, A.A. Intestinal organoids model human responses to infection by commensal and Shiga toxin producing Escherichia coli. PLoS ONE 2017, 12, e0178966. [CrossRef] [PubMed]

86. Pradhan, S.; Karve, S.S.; Weiss, A.A.; Hawkins, J.; Poling, H.M.; Helmrath, M.A.; Wells, J.M.; McCauley, H.A. Tissue Responses to Shiga Toxin in Human Intestinal Organoids. Cell. Mol. Gastroenterol. Hepatol. 2020. [CrossRef]

87. In, J.; Foulke-Abel, J.; Zachos, N.C.; Hansen, A.-M.; Kaper, J.B.; Bernstein, H.D.; Halushka, M.; Blutt, S.; Estes, M.K.; Donowitz, M.; et al. Enterohemorrhagic Escherichia coli Reduces Mucus and Intermicrovillar Bridges in Human Stem Cell-Derived Colonoids. Cell. Mol. Gastroenterol. Hepatol. 2016, 2, 486. [CrossRef]

88. Han, X.; Lee, A.; Huang, S.; Gao, J.; Spence, J.R.; Owyang, C. Lactobacillus rhamnosus GG prevents epithelial barrier dysfunction induced by interferon-gamma and fecal supernatants from irritable bowel syndrome patients in human intestinal enteroids and colonoids. Gut Microbes 2019, 10, 59-76. [CrossRef]

89. Hou, Q.; Ye, L.; Liu, H.; Huang, L.; Yang, Q.; Turner, J.; Yu, Q. Lactobacillus accelerates ISCs regeneration to protect the integrity of intestinal mucosa through activation of STAT3 signaling pathway induced by LPLs secretion of IL-22. Cell Death Differ. 2018, 25, 1657-1670. [CrossRef]

90. Zhang, Y.-G.; Wu, S.; Xia, Y.; Sun, J. Salmonella -infected crypt-derived intestinal organoid culture system for host-bacterial interactions. Physiol. Rep. 2014, 2, e12147. [CrossRef]

91. Forbester, J.L.; Goulding, D.; Vallier, L.; Hannan, N.; Hale, C.; Pickard, D.; Mukhopadhyay, S.; Dougan, G. Interaction of Salmonella enterica Serovar Typhimurium with Intestinal Organoids Derived from Human Induced Pluripotent Stem Cells. Infect. Immun. 2015, 83, 2926-2934. [CrossRef]

92. Ranganathan, S.; Doucet, M.; Grassel, C.L.; Delaine-Elias, B.; Zachos, N.C.; Barry, E.M. Evaluating Shigella flexneri Pathogenesis in the Human Enteroid Model. Infect. Immun. 2019, 87, e007401-8. [CrossRef] 
93. Drummond, C.G.; Bolock, A.M.; Ma, C.; Luke, C.J.; Good, M.; Coyne, C.B. Enteroviruses infect human enteroids and induce antiviral signaling in a cell lineage-specific manner. Proc. Natl. Acad. Sci. USA 2017, 114, 1672-1677. [CrossRef] [PubMed]

94. Roodsant, T.; Navis, M.; Aknouch, I.; Renes, I.B.; van Elburg, R.M.; Pajkrt, D.; Wolthers, K.C.; Schultsz, C.; van der Ark, K.C.H.; Sridhar, A.; et al. A Human 2D Primary Organoid-Derived Epithelial Monolayer Model to Study Host-Pathogen Interaction in the Small Intestine. Front. Cell. Infect. Microbiol. 2020, 10, 272. [CrossRef] [PubMed]

95. Good, C.; Wells, A.I.; Coyne, C.B. Type III interferon signaling restricts enterovirus 71 infection of goblet cells. Sci. Adv. 2019, 5, eaau4255. [CrossRef] [PubMed]

96. Liu, R.; Moriggl, R.; Zhang, D.; Li, H.; Karns, R.; Ruan, H.-B.; Niu, H.; Mayhew, C.; Watson, C.; Bangar, H.; et al. Constitutive STAT5 activation regulates Paneth and Paneth-like cells to control Clostridium difficile colitis. Life Sci. Alliance 2019, 2, e201900296. [CrossRef] [PubMed]

97. Majowicz, S.E.; Scallan, E.; Jones-Bitton, A.; Sargeant, J.M.; Stapleton, J.; Angulo, F.J.; Yeung, D.H.; Kirk, M.D. Global Incidence of Human Shiga Toxin-Producing Escherichia coli Infections and Deaths: A Systematic Review and Knowledge Synthesis. Foodborne Pathog. Dis. 2014, 11, 447-455. [CrossRef] [PubMed]

98. Tarr, P.I.; Gordon, C.A.; Chandler, W.L. Shiga-toxin-producing Escherichia coli and haemolytic uraemic syndrome. Lancet 2005, 365, 1073-1086. [CrossRef]

99. Hill, C.; Guarner, F.; Reid, G.; Gibson, G.R.; Merenstein, D.J.; Pot, B.; Morelli, L.; Canani, R.B.; Flint, H.J.; Salminen, S.; et al. The International Scientific Association for Probiotics and Prebiotics consensus statement on the scope and appropriate use of the term probiotic. Nat. Rev. Gastroenterol. Hepatol. 2014, 11, 506-514. [CrossRef]

100. Kim, S.-K.; Guevarra, R.B.; Kim, Y.-T.; Kwon, J.; Kim, H.; Cho, J.H.; Kim, H.B.; Lee, J.-H. Role of Probiotics in Human Gut Microbiome-Associated Diseases. J. Microbiol. Biotechnol. 2019, 29, 1335-1340. [CrossRef]

101. Zocco, M.A.; Dal Verme, L.Z.; Cremonini, F.; Piscaglia, A.C.; Nista, E.C.; Candelli, M.; Novi, M.; Rigante, D.; Cazzato, I.A.; Ojetti, V.; et al. Efficacy of Lactobacillus GG in maintaining remission of ulcerative colitis. Aliment. Pharmacol. Ther. 2006, 23, 1567-1574. [CrossRef]

102. Wilhelmi, I.; Roman, E.; Sanchez-Fauquier, A. Viruses causing gastroenteritis. Clin. Microbiol. Infect. 2003, 9 , 247-262. [CrossRef]

103. Estes, M.K.; Kang, G.; Zeng, C.Q.-Y.; Crawford, S.E.; Ciarlet, M. Pathogenesis of Rotavirus Gastroenteritis. In Novartis Foundation Symposia; Chadwick, D., Goode, J.A., Eds.; John Wiley \& Sons, Ltd.: Chichester, UK, 2008; pp. 82-100. ISBN 978-0471-49663-2.

104. Ettayebi, K.; Crawford, S.E.; Murakami, K.; Broughman, J.R.; Karandikar, U.; Tenge, V.R.; Neill, F.H.; Blutt, S.E.; Zeng, X.-L.; Qu, L.; et al. Replication of human noroviruses in stem cell-derived human enteroids. Science 2016, 353, 1387-1393. [CrossRef] [PubMed]

105. Yin, Y.; Wang, Y.; Dang, W.; Xu, L.; Su, J.; Zhou, X.; Wang, W.; Felczak, K.; van der Laan, L.J.W.; Pankiewicz, K.W.; et al. Mycophenolic acid potently inhibits rotavirus infection with a high barrier to resistance development. Antiviral Res. 2016, 133, 41-49. [CrossRef] [PubMed]

(C) 2020 by the authors. Licensee MDPI, Basel, Switzerland. This article is an open access article distributed under the terms and conditions of the Creative Commons Attribution (CC BY) license (http://creativecommons.org/licenses/by/4.0/). 